\title{
LA MEMORIA DE LOS MARGINADOS
}

\author{
María Isabel Orellana Rivera ${ }^{1 *}$
}

\section{RESUMEM:}

Concebimos el espacio del museo como un territorio en conflicto en el que diferentes relatos cohabitan y tensionan la historia oficial. Esto implica recoger la labor de diferentes actores, entendiendo que su participación no le resta legitimidad ni veracidad a los relatos. Al contrario, permite que éstos emerjan desde el imaginario y se instalen con propiedad en la historiografía. Atendiendo a esta prerrogativa, desarrollamos el programa Memorias desde la marginalidad, en el que, utilizando como metodología la museología participativa, definimos 3 temáticas: infancia, locura y familiares de detenidos desaparecidos. Aquí expondremos la tercera, en la que se desarrollaron tres períodos de trabajo $(2009,2010$ y $20 \mathrm{II})$. Durante este tiempo construimos un espacio en el que los/as participantes se re-conocieron en una dimensión más allá de su condición política o sociológica, agregaron historicidad a sus relatos $y$ empatizaron con otros/as familiares en función de las nuevas informaciones emergidas de estas narraciones.

\section{PALABRAS-CLAVES:}

Memoria. Museología participativa. Patrimonio. Familiares detenidos desaparecidos.

\begin{abstract}
:
We conceive of the realm of the museum, as a territory in conflict, in which differing stories cohabit and charge the official history. This requires that we bring together the work of different actors, understanding that their participation doesn't subtract legitimacy or veracity from the accounts. On the contrary, it allows these to emerge from the imagination and install themselves with propriety in historiography. Attending to this prerogative, we develop the program 'Memories from exclusion, in which, employing the methodology of participative museology, we define 3 subject matters: infancy, insanity, and the families of missing detainees. Here we expound the third of these in which three periods of work were undertaken $(2009,2010, y$ 20II). During this time we constructed a space in which the participants got to know themselves anew in a dimension outside of their sociological or political condition. They added historicity to their accounts, and empathized with other family relations, in function of new facts that emerged from these narrations.
\end{abstract}

\section{KEY-WORDS:}

Memory. Participative museology. Heritage. Relatives of missing detainees.

I * Directora del Museo de la Educación Gabriela Mistral, Santiago do Chile. 
El Museo de la Educación Gabriela Mistral (MEGM) de Santiago de Chile es una institución única en su género en nuestro país que desarrolla sus actividades en una zona típica (denominación otorgada por el Consejo de Monumentos Nacionales), en el Barrio Yungay, un sector de habitaciones populares y de clase media que cobija una población muy diversa. Este lugar en los últimos años ha visto, además, llegar una cantidad importante de inmigrantes, muchos de los cuales viven en condiciones precarias, provenientes principalmente de Perú, Bolivia, Ecuador y Colombia, los que aportan también con su diversidad al mosaico cultural en el que se ha transformado esta parte de la ciudad. Este barrio data de 1839, a principios del siglo $X X$ albergó a la clase alta de Santiago, la que paulatinamente fue trasladándose hacia el Oriente, de esto da cuenta todavía su arquitectura, expresada en algunas casas señoriales que han resistido al paso del tiempo, al abandono del Estado y su mal manejo urbanístico y a las catástrofes naturales ${ }^{2}$. Paralelamente, debido a las transformaciones que ha experimentado este espacio, asistimos, desde hace unos diez años aproximadamente, a la emergencia y consolidación de una ciudadanía cada vez más empoderada, que defiende y gestiona su patrimonio material (territorio, arquitectura y monumentos históricos) e inmaterial (formas de organización social y economía de pequeña escala). Todo esto en el marco de un escenario de efervescencia social en que las manifestaciones estudiantiles y de otras organizaciones de base han instalado demandas sociales que en la actualidad se consideran centrales a la hora de analizar las causas de las grandes desigualdades que atraviesan al país, como por ejemplo la calidad y equidad en educación, una nueva constitución que norme la convivencia social y un estado más explícito en materia de derechos humanos e igualdad de géneros.

Ahora bien, en este contexto geográfico y social, nuestro museo, como heredero de la nueva museología y de la museología crítica, articula su trabajo sobre tres ejes temáticos (historia, memoria y patrimonio), con los que busca transformarse en un instrumento al servicio de la sociedad e instalar temáticas que contribuyan a aumentar e interrogar sus colecciones. En este marco se desarrolla el trabajo que describiremos a continuación. Pero estas tensionen que recorren el territorio en el que se emplaza en museo no son ajenas a la naturaleza misma de la institución museal, sobre todo si entendemos a esta última, por una parte, como un espacio que contiene físicamente - en sus objetos- $y$ simbólicamente - en sus relatos- parte de la memoria de una sociedad y, por otra, como un territorio en permanente conflicto en el que diferentes relatos cohabitan y tensionan la historia oficial, dando cuenta de cosmovisiones y puntos de vista diversos acerca de un mismo proceso histórico. En este sentido, nuestra institución busca actuar como una plataforma de visibilización de acontecimientos, personas y procesos que permita construir y de-construir diversas visiones históricas y sociales. Esto implica repensar la labor de los historiadores, pues,

Aunque analistas y descriptores de procesos históricos... no escapan a la lucha por otorgar sentidos al pasado, ni a las exigencias del presente en mirar hacia atrás... Su práctica profesional les otorga una mirada particular, con relativo peso en el imaginario público: el utillaje científico de la profesión no es (no debería ser) un antídoto contra la subjetividad, sino un reaseguro para el lugar desde el que la enuncian. Como historiadores, nuestras herramientas profesionales no evitan el sesgo, sino que dan rigor y autoridad a un enfoque particular (LORENZ, 2007, p. 96).

2 Los terremotos de marzo de 1985 y de febrero de 2010 destruyeron gran parte de los inmuebles. Se suma a esto la intervención de grandes empresas inmobiliarias que han construido edificios en altura que tensionan e impactan tanto en la arquitectura (constituida principalmente por casas bajas de fachada continua) como en la calidad de vida de sus habitantes. 
Por su parte, la participación de los protagonistas que dan vida a la historia que se expresa en estos enfoques particulares, no le resta legitimidad ni veracidad a los relatos.Al contrario, permite que éstos emerjan desde el imaginario y se instalen con propiedad en la historiografía, pues como este mismo autor nos recuerda "la historia no sólo diseca mitos, sino que puede aportar elementos para reforzar o atraer a la luz causas, hechos y actores olvidados o extintos” (LORENZ, 2007, p. 97).

Incluir la memoria en el ejercicio historiográfico no es tarea fácil, porque ésta coloca al investigador

frente a un replanteo de sus prácticas y de la concepción acerca de la historia, en relación con la sociedad, y a una 'apertura' a otras formas de hacer historia. La 'memoria' como objeto, ejercicio y fin lleva a un redimensionamiento de la actividad de los historiadores que implica el abandono de una posición de superioridad o aislamiento frente a otras formas de conocimiento... la 'memoria', en tanto ejercicio colectivo, quita de hecho el monopolio y la autoridad para hablar acerca del pasado en base a determinados pergaminos académicos o institucionales (LORENZ, 2007, p. 97).

Bajo esta premisa planificamos el programa Memorias desde la marginalidad, que busca relevar la diversidad de narraciones que conforman los "grandes relatos nacionales", permitiendo que la comunidad local tenga participación directa en la generación tanto de los contenidos tratados en el museo como en el acopio del acervo documental y patrimonial que la institución custodia, conserva y difunde, aumentando de esta forma nuestras colecciones, principalmente a través del registro de relatos e imágenes. Para esto, y haciéndonos cargo del bicentenario de la República conmemorado el año 2010, definimos como objetivo principal "recoger relatos de grupos a los que el Estado chileno, en algún momento de su historia como nación independiente, les ha negado la posibilidad de participar de los procesos de reconstrucción de memoria histórica o de insertarse en ellos". De esta forma, nos hacemos cargo de una noción de museo integral (CHAGAS, 2007) y consciente del territorio donde se emplaza, en que la sociedad y sus preocupaciones ocupan un espacio significativo a la hora de generar sus actividades y sus políticas institucionales. Esto supone una reflexión acerca de los mecanismos de elaboración y reproducción de la memoria, la identidad y el poder que la invisibiliza, fundamenta o legitima.Así, el museo enriquece su acervo patrimonial y se abre a una nueva perspectiva histórica al reconstruir procesos y referentes simbólicos que transforman la historia local en un componente activo de la historia nacional. Esto permite, a su vez, un diálogo colectivo en torno al patrimonio y la historia de las comunidades.

De este modo, entender la memoria como construcción intelectual implica, por una parte, hacerse cargo de procesos subjetivos, anclados en experiencias propias y en marcas simbólicas y materiales y, por otra, aceptar que se trata de un objeto de disputas, conflictos y luchas, que no puede desvincularse del rol activo y productor de sentido que le otorgan los participantes en dichos procesos (JELIN, 2002). Atendiendo a nuestro rol de museo dedicado a la historia, buscamos historizar estas memorias, otorgándoles sentido más allá del relato individual, haciéndolas formar parte de un contexto cultural en el que se revitalizan como parte de la memoria emblemática de la que nos habla Stern (2002). El MEGM, busca así, transformarse en un lugar de encuentro y diálogo, en que historia, memoria y patrimonio se articulen para dar forma a un espacio reparatorio en sí mismo, abierto a la construcción de ciudadanías diversas y abocado a la tarea, como señalaba Gabriela Mistral, de construir la paz en la mente de las personas.

Por las razones antes expuestas, el año 2008 dimos inicio al programa "memorias desde la marginalidad", instancia que apunta a visibilizar y "oficializar" los 
discursos de una parte de la sociedad, generalmente, ausente del espacio museal. El propósito de este programa está en sintonía con la política general del museo que apunta en dos direcciones: primero, otorgarle a la comunidad un rol activo y permanente en la construcción de saberes y en la definición del patrimonio cultural $^{3} y$, segundo, cuestionar al museo desde la museología crítica,

teoría que propone que museología tradicional así como sus principios básicos (v.gr., musealidad) son un producto de la sociedad en las cuales son creados, es decir, definidos por el contexto histórico, político y económico en el cual los museólogos y los museos están inmersos. En este sentido el marco conceptual va más allá del establecido por las ciencias de la información para proponer un enfoque histórico-dialéctico de la relación entre los seres humanos y su realidad. Es decir, la museología crítica va más allá del aspecto comunicacional de los objetos y las instituciones para analizar las determinaciones históricas de esta cualidad (NAVARRO, 2006, p. I).

Para esto, seleccionamos tres áreas de trabajo: infancia, locura y parte de la Agrupación de Familiares de Detenidos Desaparecidos (AFDD). Ahora bien, una pregunta que legítimamente puede surgir entre nuestros lectores y lectoras es por qué elegir estos actores y no otros que también forman parte de los grupos marginados de la sociedad; la respuesta se relaciona con la posición que ocupan frente al Estado. A los tres segmentos seleccionados, de alguna manera el garante por esencia del Bien Común les ha negado en algún momento de la historia de Chile el derecho a la memoria. A los primeros, porque aludiendo a "sus escasos años" y falta de "experiencias" no se les considera con las vivencias suficientes para participar de los procesos en torno a la memoria histórica; a los segundos, porque dada su condición siquiátrica se les despoja de sus derechos civiles y se les considera interdictos ante la ley y alejados de la realidad que los circunda; a los últimos, porque al negarse durante un período de nuestra historia el hecho de la desaparición, se les negó también su condición de víctimas, en tanto familiares de los ausentes. Estamos ciertos que hay muchos otros actores de los cuales los procesos de reconstrucción de memoria histórica tampoco se han hecho cargo: pueblos originarios, mujeres campesinas, otras sexualidades, personas en situación de calle, etc. Es por esto que no pretendemos instalar la tesis de que las categorías escogidas son las que definen la marginalidad en términos históricos; simplemente, las hemos seleccionado porque, a nuestro juicio, esta noción de marginalidad las contiene. Por lo mismo, justificamos esta elección con razones que emanan de la naturaleza misma de estos actores, las que a continuación trataremos de explicar.

\section{Infancia}

Partiendo de la premisa de que niños y niñas son poseedores de derechos culturales y como señala Meirieu (1998), no son objetos en construcción, sino sujetos que se construyen, buscamos en el espacio del museo erradicar falsas representaciones, entre ellas la que señala que debido a su falta de madurez o conocimiento no pueden reflexionar acerca de temas complejos como la memoria

3 Cabe hacer notar que nuestro trabajo con la comunidad se vincula estrechamente con el proceso de renovación, iniciado el año 2000, que culminó con la reapertura del museo en marzo de 2006, después de $2 \mathrm{I}$ años de interrupción. El museo había sido cerrado en 1985 a causa del terremoto que afectó ese año a la zona central del país y que dañó estructuralmente al edificio. Desafortunadamente, no se generó ninguna política pública hasta fines de la década de los 90 que permitiera su reapertura. El año 2000 la Subdirección Nacional de Museos, dependiente de la Dirección de Bibliotecas, Archivos y Museos, incluyó a nuestra institución en un plan general de renovación que condujo a la modernización de los 23 museos regionales y especializados que funcionan bajo su tutela. Para saber más, leer: Orellana Rivera (20I2). 
o el patrimonio. En el contexto de las actividades desarrolladas en el museo, sus relatos nos permiten darnos cuenta que tienen una forma de ver a su familia, a su escuela, a su barrio, a su país o a los acontecimientos que ocurren en el mundo, la que se expresa en opiniones sobre temas tan diversos como: la calidad de la educación, la política contingente, las guerras, la depredación del medio ambiente y el hambre. Desde sus representaciones, construyen también un esquema de la realidad cuya conformación no sólo se compone de sus vivencias y recuerdos, sino también de los relatos que "otros" inevitablemente van instalando en ellos y ellas. Lo que escuchan de sus padres, madres, abuelos, profesores, pares y demás personas de su entorno, dibuja en sus vidas una forma de apreciar y percibir la realidad. A partir de esto, generan discursos y un conjunto de valores que los convierten en portavoces válidos frente al resto de la sociedad.

\section{Locura}

Reconocida primero como una enfermedad del alma y, desde Freud en adelante, como una enfermedad mental (FOUCAULT, I 972), la locura estigmatiza a quienes la padecen, convirtiéndolos en objeto de burlas o de temor o, simplemente, invisibilizándolos. Sin embargo, esto no siempre fue así, como muy bien lo describe Foucault (1972) en su libro Historia de la locura en la época clásica, el estatus del loco en la historia pasó de ser el que ocupaba un lugar aceptado en la sociedad -incluso reconocido en el orden social- a ser el excluido, que debía ser encerrado y confinado entre cuatro paredes. Afortunadamente, esta representación de los enfermos siquiátricos también se ha ido transformando y es así como, en la actualidad, existen espacios como el Hospital de Día, que les permite recibir ayuda terapéutica e interdisciplinaria durante el día sin necesidad de abandonar su entorno familiar. Ahora bien, cualquiera sea el tipo de trastornos que manifiesten los pacientes siquiátricos, forman parte constitutiva de la sociedad que los aísla y segrega. Con su realidad fragmentada y dolorosa -independientemente de sus desequilibrios mentales, su percepción distorsionada del ambiente que los rodea o su pérdida del autocontrol- también intervienen y se ven afectados por los acontecimientos que atraviesan al país. Desde su alteridad, son parte del desarrollo de la historia. En la complejidad de su razonamiento subyacen recuerdos, vivencias, traumas, silencios, sombras, nombres, melodías, aromas, que conforman también parte de la memoria olvidada del país. Este es el segmento con el que menos hemos podido trabajar, en gran medida, por la dificultad para articular un trabajo coordinado con las instituciones que los acogen. Sin embargo, los pocos encuentros realizados (tres a la fecha con enfermos tratados en régimen de Hospital de Día) han resultado altamente positivos desde el punto de vista del diálogo que se genera y de las respuestas que ellos proponen a cada actividad.

En cuanto a las características de las personas con las que hemos trabajado, se trata de enfermos duales, es decir, de pacientes que, además de presentar alguna patología de base, están en tratamiento por una adicción. En lo que a resultados se refiere, si bien hemos tenido algunos acercamientos muy satisfactorios, es un proceso en desarrollo, en el que estamos ciertos tenemos una tarea pendiente, sobre todo en lo que dice relación con establecer nexos institucionales que nos permitan trabajar un cronograma a largo plazo.

\section{Familiares de detenidos/as desaparecidos/as}

Escuchar las voces de los familiares de los detenidos desaparecidos, más allá del acto reparatorio que involucra poner atención en su relato como víc- 
timas de la dictadura de Pinochet (1973 - 1990), implica adentrase en lo que Stern denomina la memoria emblemática, que "no es una sola memoria [...] Más bien es una especie de marco, una forma de organizar las memorias concretas y sus sentidos, y hasta organizar los debates entre la memoria emblemática y su contra-memoria" (STERN, 2002, p. 3). Se trata de conocer a quien partió desde el relato de quienes lo o la conocieron y de entender el rol de sus familiares en tanto personas con una historia personal que antecede el hecho de la desaparición. Todo esto busca convertir a estos familiares en protagonistas de sus propias memorias, explorando otras ópticas de análisis desde la noción de lo que Stern denomina "las memorias sueltas". Según este autor

todos tenemos en nuestras vidas una multitud de experiencias, $y$ en nuestras cabezas una multitud de memorias más o menos sueltas desde una perspectiva social. Son éstas una serie de recuerdos para nosotros significativos, y hasta fundamentales para definir quiénes somos. Pero no tienen mayor sentido -no necesariamente- fuera de un ámbito muy personal (STERN, 2002, p. I).

Cuando una parte de la sociedad les otorga un sentido colectivo las hacemos formar parte de esta memoria emblemática que nutre la historiografía desde la experiencia de los protagonistas de los procesos analizados.

En este marco de reflexión, la necesidad de devolverles a estos familiares su condición de sujetos históricos se fundaba en una hipótesis inicial: cuando las víctimas desaparecen, sus cercanos también de cierta manera se "desvanecen", atribuyéndoseles un nuevo rol marcado por la historia reciente (el/la que busca a quien ya no está), más que por sus vivencias pasadas. Es por esto que, haciendo uso de técnicas de trabajo de campo, "hurgamos" en sus relatos para insertarlos en la historia "oficial" del museo $y$, de paso, enriquecer nuestras colecciones patrimoniales a partir del registro de relatos audiovisuales y la digitalización de imágenes que dan cuenta de la historia reciente del país. Utilizamos para ello las herramientas que el museo como espacio de conservación y difusión patrimonial nos ofrece. Estas herramientas permiten que los participantes hablen de sí mismos, reflexionen acerca de sus propias experiencias y las de los otros miembros del grupo y expresen libremente sus ideas.

Una de las primeras interrogantes que nos planteamos cuando iniciamos este programa fue ¿cómo activar estas memorias para que circulen y se asienten en un universo colectivo? Buscamos la respuesta en la tesis de Stern (2002, p. 12) de los nudos convocantes de memoria:

Seres humanos y circunstancias sociales que exigen que se construyan puentes entre el imaginario personal y sus memorias sueltas por un lado, y el imaginario colectivo y sus memorias emblemáticas por otro. Estos nudos imponen una ruptura de nuestros hábitos más o menos inconscientes, los reflejos de la vida cotidiana que corresponden al famoso 'habitus' del sociólogo Pierre Bourdieu.Al imponer la ruptura, los nudos nos exigen pensar e interpretar las cosas más conscientemente.

Esto nos permitió, además, forzar la aparición de relatos individuales en primera persona y no sólo en función de la relación de los/as participantes con los/as víctimas. Cabe hacer notar que uno de nuestros primeros obstáculos al iniciar el trabajo, a pesar de la manera cómo éste estaba planteado, fue hacer entender a estas personas que la finalidad del programa era relevar sus experiencias personales más allá de su condición de familiares de un desaparecido o desaparecida. Paralelamente, seleccionamos una metodología que nos permitiera construir nuevos conocimientos a partir de estos discursos. 


\section{Metodología}

Incorporar los relatos de los visitantes en la producción del conocimiento que se genera en el museo implica abrirse a nuevas metodologías y ópticas de análisis. La museología participativa permite al museo vincularse con la comunidad y nutrirse de la discusión generada desde sus públicos, pues sus estrategias ponen el acento en los protagonistas y sus relatos. Esta intención permite actuar sobre la relación que se genera entre el museo y sus diferentes audiencias, las que se sienten acogidas, reconocidas e interpeladas durante el proceso.

Entendemos por museología participativa una estrategia explícita de incorporación de la comunidad al museo, noción que tiene como referente esencial la participación ciudadana y lo que Bonfil Batalla (1993) denomina la apropiación cultural. Se trata de una instancia de visibilización de procesos culturales en los que se expresa y reconoce la memoria como un componente activo de la historia que se construye en el seno del espacio museal. Esto permite incorporar una diversidad de interlocutores que se relacionan con la institución desde su propia especificidad y campo de acción, estimulando, además, el uso de los entornos culturales como espacios de educación para la democracia y para la paz.A continuación describiremos parte de los resultados de este proceso.

\section{Resultados}

El trabajo se estructuró a largo plazo, por lo que se extendió por cuatro años, en los que se llevaron a cabo tres períodos de trabajo $(2009,2010$ y $20 \mathrm{II})$ de 6 sesiones cada uno -con la participación de 35 personas- y un período de evaluación final (20I2), en el que los y las participantes aportaron más antecedentes y analizaron el proceso llevado a cabo los años anteriores ${ }^{4}$.

La tarea de abordar temas tan complejos como las consecuencias en la ciudadanía de la violencia política ejercida desde el Estado, implica escoger cuidadosamente tanto las herramientas como las estrategias de trabajo, de manera de no remover heridas ni generar situaciones de stress emocional que fragilicen a los y las participantes. Ahora bien, en el entendido de que en este proceso afloraría inevitablemente el dolor, la finalidad nunca fue escudriñar $y$ ahondar en el sufrimiento -que de manera evidente permanece, dadas las circunstancias de la pérdida y la falta de justicia en la mayoría de los casos- sino intentar descubrir y completar la figura de los familiares en sus variados contextos de vida. Utilizar para este propósito el espacio del museo no fue azaroso, dado que esta institución representa la memoria de un gran número de personas que forjaron los procesos históricos en la cotidianidad del acto educativo. Las voces de los familiares fueron las encargadas de completar parte de estas historias a través de relatos, objetos y fotografías que le dieron sentido y contexto a las memorias que de allí surgieron. Las actividades desarrolladas fueron las que habitualmente se abordan con los usuarios y usuarias del museo: talleres patrimoniales (trabajo con fotografías personales y palabras significativas; utilización de objetos para recontextualizar y museografiar procesos históricos y vivencias personales, escritura de cartas y diarios de vida, etc.), visitas guiadas, exhibición y registro de videos, talleres de dibujo, cuenta cuentos, encuestas de evaluación y diaporamas de finalización. Todos estos elementos ahora forman parte de nuestras colecciones, especialmente del archivo audiovisual.

4 Este trabajo culminará oficialmente este año con la entrega al archivo de la Agrupación de Familiares de Detenidos Desaparecidos de los registros recogidos y de una impresión digital a tamaño real del mural colectivo realizado durante el año $201 \mathrm{I}$. 
En cuanto al objetivo de esta parte del programa, éste consistió en relevar las historias de los detenidos desaparecidos y de sus familiares, a través del recuerdo y la narrativa, promoviendo un relato con sentido nuevo para todos los involucrados. Los objetivos específicos, que a nuestro juicio se lograron a cabalidad, apuntaron en dos direcciones: generar instancias de trabajo que permitieran el diálogo; y registrar, a través de diversos medios audiovisuales, esta experiencia de rescate de la memoria, de manera de aumentar el fondo patrimonial del museo.

Un aspecto importante se basó en el manejo de las emociones, dado que las temáticas favorecían que los participantes se despojaran de la actitud permanente de regular sus emociones -ese "no llorar" al que aludían al inicio del programa- para dar rienda suelta a sus relatos, muchos de los cuales los fragilizarían frente al resto. Esto tuvo un impacto significativo en cómo ellos se percibirían de ahora en adelante, pues como lo señala Silva (2009, p. 24), refiriéndose al caso argentino, cuando nos adentramos en

las prácticas y representaciones de los familiares es posible descubrir un laboratorio de ideas (MUEL-DREYFUS, 1996); un plano donde resalta con nitidez la regulación de las emociones, la transformación del dolor en efectivas acciones que descartan el uso de la violencia física; una dimensión que permite observar los diferentes recursos (políticos, culturales, religiosos, escolares, de género, clase, etc.) a los que los individuos echan mano para sobreponerse a las experiencias extremas, para ajustar las dramáticas vidas a un mundo que, pese a todo, gira.

En relación con los logros, creemos que se cumplieron los objetivos iniciales, pues a través de nuevos grados de conocimiento -en función del descubrimiento de otros aspectos de sus vidas- agregaron historicidad a sus relatos y empatizaron con las historias de otros familiares. La finalidad de entrar en esta dimensión más íntima, pero igualmente política, buscaba huir

De los estereotipos filosofantes de pensar la categoría 'familiar' globalmente. [La idea era dejar en evidencia en estos encuentros que] contra el estilo corriente que al inicio de textos y exposiciones prioriza un sofisticado marco 'teórico/epistemológico' para echar al margen un esbozo de 'referente empírico' que sólo termina sirviendo de ejemplo o descripción [...] los desafíos de mayor peso analítico, comprensivo, teóricos si se quiere, emanan de la explicitación de las elecciones más elementales de la investigación: un lugar, personas, tiempo, limitaciones, descubrimientos (SILVA, 2009, p. 25).

Cada período de trabajo culminó con la realización de un producto que formaría parte de los fondos documentales del museo. El primer año, denominado "palabras y objetos para no llorar", los participantes escribieron una carta a sus desaparecidos o desaparecidas. El segundo, denominado "la memoria está llena de olvidos", escribieron una carta a los victimarios o victimarias. El tercero, denominado "la vida hecha tira" crearon un mural colectivo compuesto por cuadrículas de óleo sobre tela en las que expresaron, mediante el lenguaje plástico, sus historias individuales (recuerdos, entornos significativos, anhelos, miedos, etc.). Éstas fueron unidas hasta convertirlas en un solo elemento museográfico que contenía los relatos en una historia colectiva. En relación con las temáticas de estos lienzos, el mar fue siempre un tema recurrente, en unos casos, como el espacio que acogía concreta y simbólicamente el cuerpo de sus familiares $y$, en otros, como el espacio hostil que se los arrebataba para siempre, borrando cualquier vestigio de la desaparición. Durante el proceso de creación 
de estas obras, cada participante fue entrevistado/a individualmente para dejar registro de la historia propia. Ambas acciones fueron muy importantes en esta última etapa, pues nos permitieron, por un lado, relevar parte de la diversidad de lenguajes (en este caso, oral y gráfico) en los que la historia puede ser narrada en el espacio del museo y, por otro, enfatizar la idea de que la historia "oficial" está compuesta por múltiples historias fragmentadas, así como la memoria emblemática se compone de múltiples memorias sueltas.

Por todo lo anterior, consideramos que se cumplieron los objetivos trazados, pues pudimos aproximarnos a "los y las que recuerdan a los y las que no están" en su calidad de sujetos culturales con historia propia. Recorriendo estos territorios de memoria construimos conocimientos y consolidamos un nuevo espacio de discusión. Sin embargo, la necesidad de expresar el dolor de la desaparición estuvo siempre presente. Esto se transformó en una oportunidad para "completar" las historias y poner en valor aspectos importantes para ellos y ellas (educación, niñez, visión del país y del resto de los ciudadanos, etc.) situando la desaparición como parte del contexto global de sus vidas. El impacto positivo que este programa tuvo en los participantes se reflejó en las respuestas a las encuestas de evaluación realizadas después de cada período de trabajo: "repetir la experiencia"; "que exista una continuidad";"que exista mayor concurrencia [...]".

Otro resultado importante del programa fue el aprendizaje obtenido por los y las integrantes del equipo que ejecutó el proyecto, quienes tuvieron que adaptarse tanto a las características de los participantes como a la diversidad y profundidad de contenidos de los distintos relatos. Algunas de las enseñanzas que acarreó el trabajo directo con este público fueron: entender que lo que en algún momento aparece como contradictorio se puede volver una oportunidad para develar otras historias; que los tiempos de escucha son fundamentales cuando se trata de capturar memorias; $y$ que tiene que haber un manejo certero de las propias emociones para empatizar con los protagonistas del relato sin convertir la participación de las mediadoras en un discurso auto-referente o carente de significados. Otro aprendizaje significativo tiene que ver con la toma de conciencia de que cada espacio tiene su propia singularidad; en el caso del museo, se trata de un territorio social, cultural y pedagógico, no de un espacio terapéutico y, si bien, al final pudo obtenerse un resultado sanador, nuestro fin apuntaba a la reparación en términos históricos no personales.

Para finalizar es importante referirse a la interrogante de por qué un museo dedicado a la historia de la educación tendría que hacerse cargo de estos temas. Proponemos tres respuestas posibles: primero, la temática de la memoria forma parte de la naturaleza del museo y de la problemática del barrio en el que éste se emplaza; segundo, un programa de estas características nos permite atraer nuevos públicos y enriquecer nuestras colecciones con objetos contemporáneos; y tercero, desde la perspectiva de la museología crítica, estas acciones nos ayudan a incorporar nuevos temas, aportando otras miradas sobre nuestras colecciones y nuestra trama narrativa. Por lo tanto, la respuesta a esta interrogante se funda en el rol que, como equipo de trabajo, le atribuimos a este establecimiento: un espacio conectado con su entorno territorial y simbólicamente, capaz, por una parte, de generar transformaciones sociales a pequeña escala y, por otra, de constituirse en un lugar de encuentro y de expresión de relatos diversos, que promuevan una educación con sentido ético y aumenten el conocimiento histórico. Así, con las herramientas propias del museo, buscamos hacer emerger memorias diversas y plurales y generar nuevos lazos con la comunidad local, dándole un sentido más amplio al patrimonio, a los procesos 
históricos que lo atraviesan y, sobre todo, a las colecciones que albergamos. En este recorrido buscamos también entender el patrimonio, desde la dimensión del conflicto planteada por Bonfil Batalla (2004), asumiendo que es tarea del museo de-construir ciertas representaciones en torno a él y a quién o quiénes deberían participar en su definición.

\section{Referencias}

BONFIL BATALLA, Guillermo. Implicaciones éticas del sistema de control cultural. In: OLIVÉ, L. (Ed.). Ética y diversidad cultural. México: Fondo de Cultura Económica, 1993. p. 195-204.

BONFIL BATALLA, Guillermo. Pensar nuestra cultura. In: ANTOLOGÍA sobre cultura popular e indígena: lecturas del seminario Diálogos en la Acción: primera etapa. México: CONACULTA, 2004. Disponível em: <http://sic.conaculta.gob. $\mathrm{mx} /$ documentos/853.pdf>. Acesso em: I 4 dez. 2013.

CHAGAS, Mario. Museos, memorias y movimientos sociales. In: SEMINARIO SOBRE PATRIMONIO CULTURAL, 9., 2007, Chile.Anais... Chile: DIBAM, 2007. Disponível em: <http://www.dibam.cl/Seminario_2007>.Acesso em: I5 ago. 2013.

FOUCAULT, Michel. Histoire de la folie à l'âge classique. París: Gallimard, 1972. JELIN, Elizabeth. Los trabajos de la memoria. Madrid, España:SigloVeintiuno Editores, 2002. LORENZ, Federico. Combates por la memoria: huellas de la dictadura en la historia. Buenos Aires: Editorial Capital Intelectual, 2007. (Colección claves para todos).

MEIRIEU, Philippe. Frankenstein educador. Barcelona: Laertes, 1998.

NAVARRO, Oscar M.A. Museos y museología: apuntes para una museología crítica. In: CONGRESSO ANUAL DEL ICOFOM, 29., 2006, Córdoba.Anais...Argentina: Conselho Internacional para Museologia, 2006. Disponível em: <http://www.icofom-lam. org/files/museos_y_museologia_critica_-_copia_2.pdf.>.Acesso em: I0 jan. 2013.

ORELLANA RIVERA, María Isabel.Identidades y memorias en diálogo con la comunidad. Cabás: Revista del Centro de Recursos, Interpretación y Estudios en materia educativa (CRIEME) de la Consejería de Educación, Cultura y Deporte del Gobierno de Cantabria, n. 8, dic. 2012. Disponível em: <http://revista muesca.es/index.php/articulos8/248-identidades-y-memorias-en-dialogo-con-la-comunidad>.Acesso em: 13 dez. 2013.

SILVA, Ludmila. No habrá flores en la tumba del pasado. La Plata, Argentina: Ediciones Al Margen, 2009.

STERN, Steve. De la memoria suelta a la memoria emblemática: hacia el recordar y el olvidar como proceso histórico (Chile, 1973-1998). In: JELIN, Elizabeth (Ed.). Las conmemoraciones: las disputas en las fechas "in-felices". España: S. XXI de España Ed., 2002. p. I I-33. Disponível em: <http://www.lapetus.uchile.cl/lapetus/archivos/I 302552396stern.pdf. >.Acesso em: I 5 jan. 20 I4. 